號五十二第誌雜會學類人京東

シコ比ル種其荘ナ余カ小踓ザカ列

少卜 $\mid$ 卜 简 ナ 絞 内

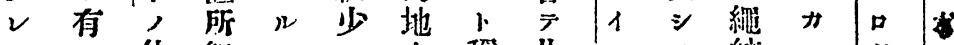

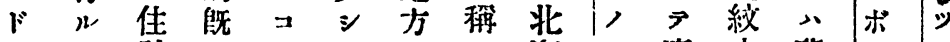

七八跡 $三$ 卜

如

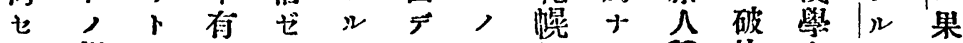

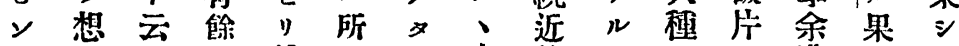

竪像子, 然ナル中傍コ,

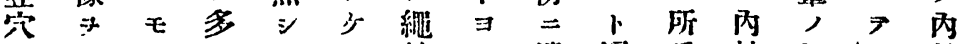

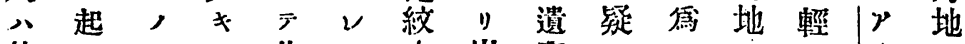

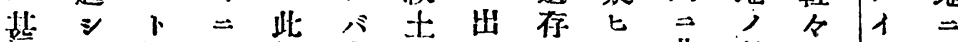

多 $、$ 同至地太器

埋其檄 $\nu$ 方古,

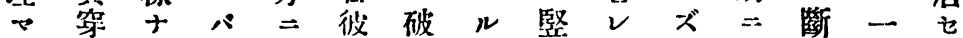

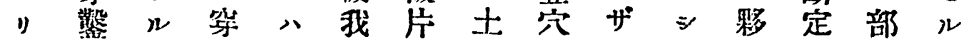

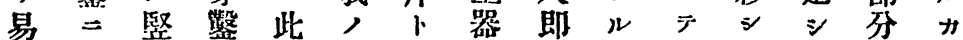

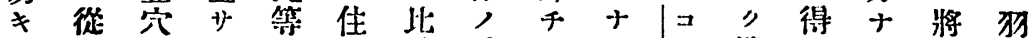

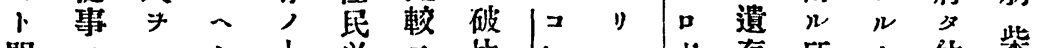

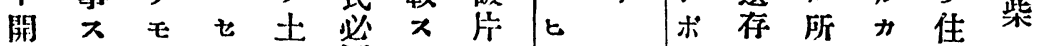

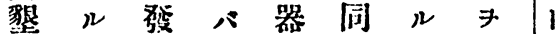

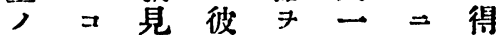

篇卜父出ノ其 $\vec{\gamma}$ 任

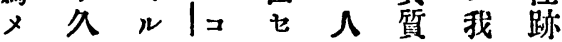

圖 二. 第

䍖

第
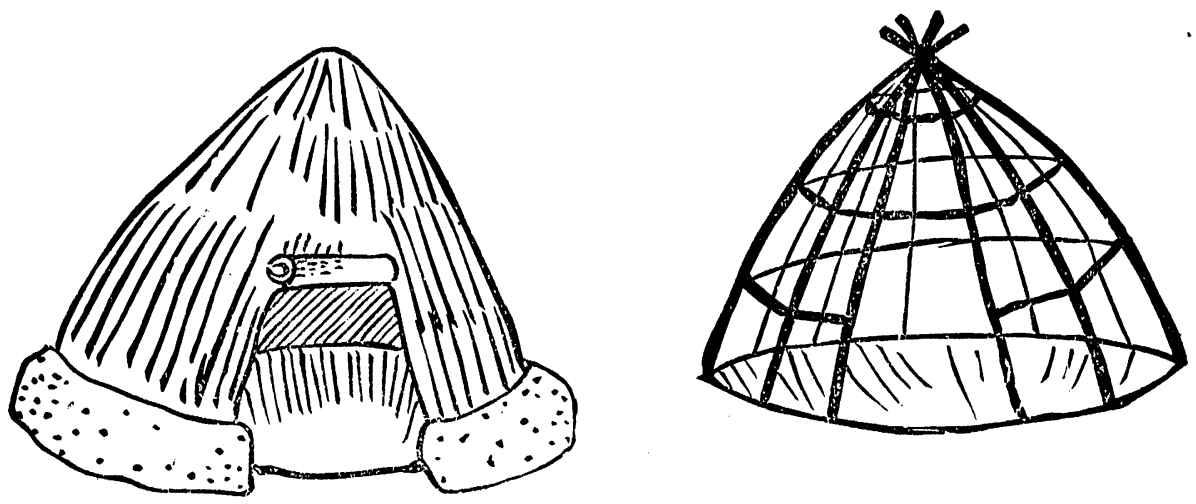


\section{月三年 一十二治明}

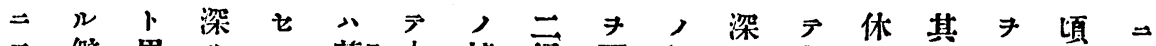

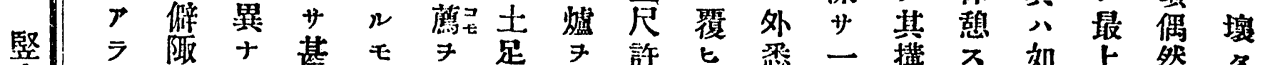
穴 ズ,

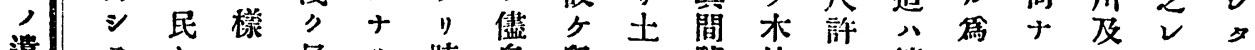

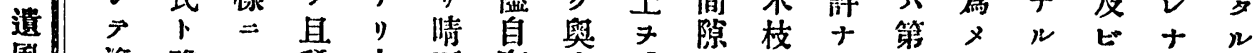

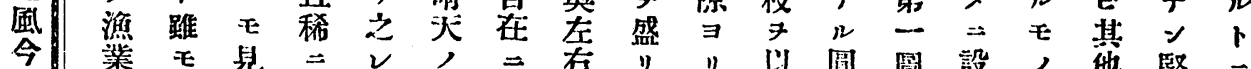

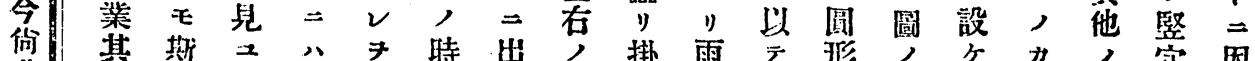
荘花

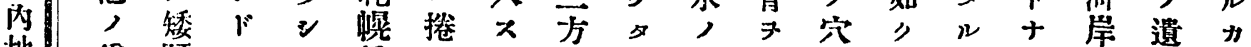

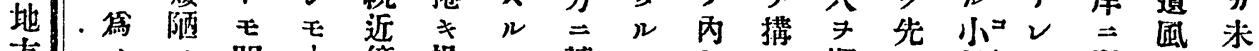

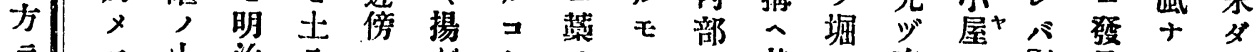

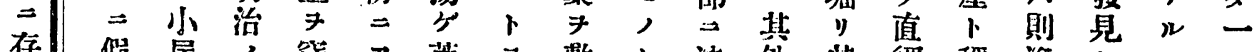

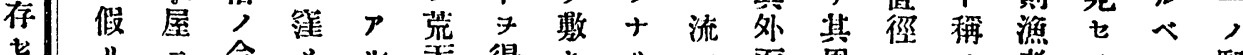
も

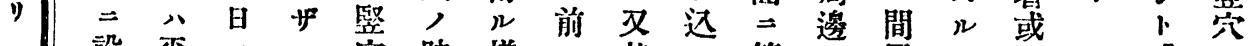

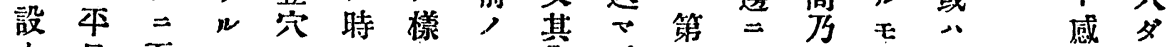

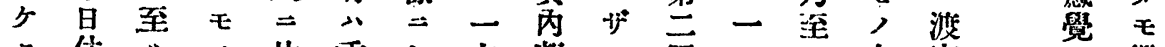

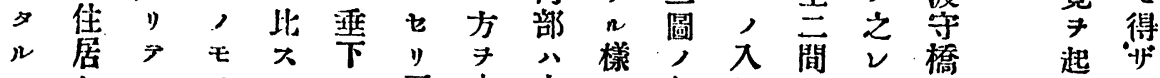

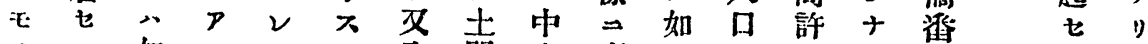

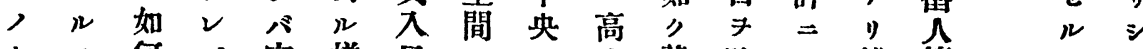

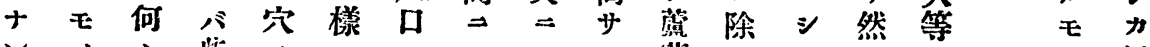

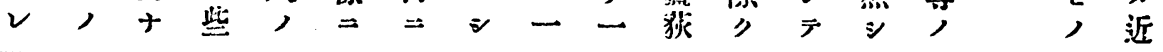

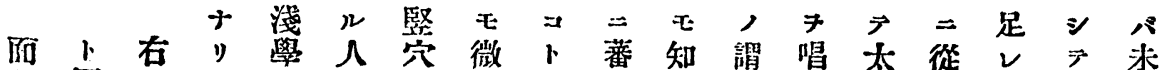

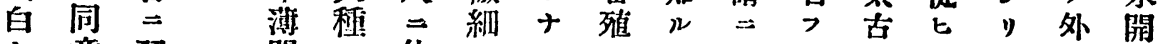

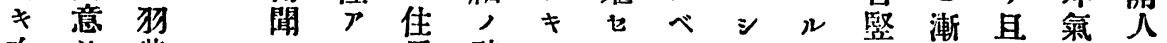

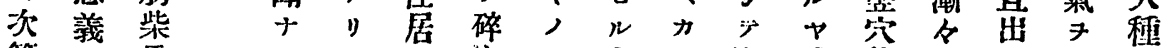
第十 氏

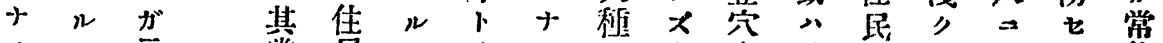

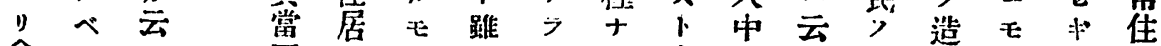
余

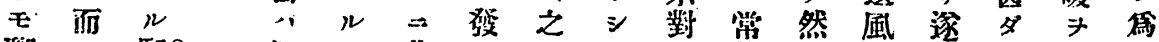

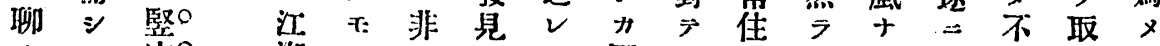

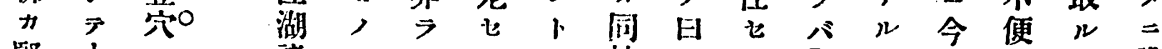

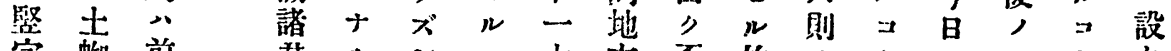

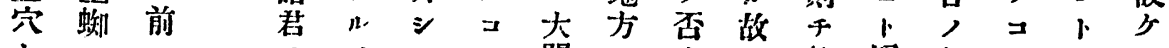

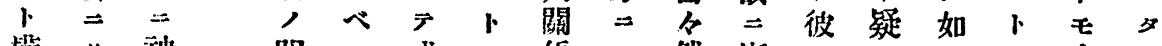

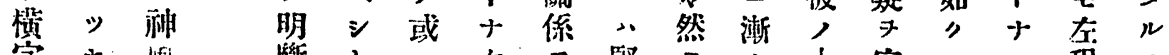

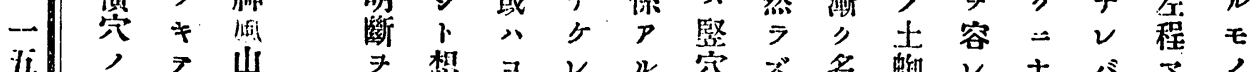
望住，， 山 E 嬑が 詩 ヘ

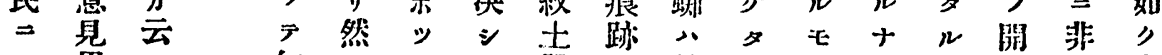

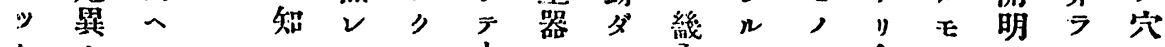

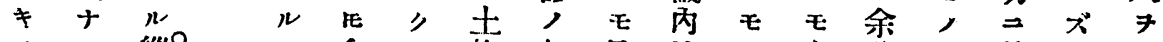
$\nabla$ 縱 管 


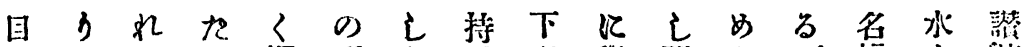

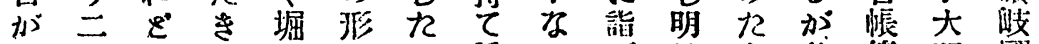

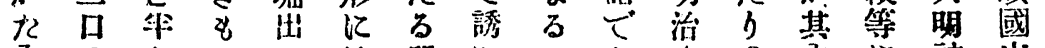

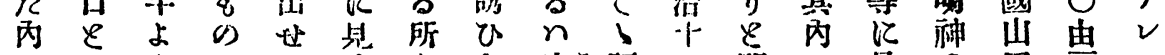

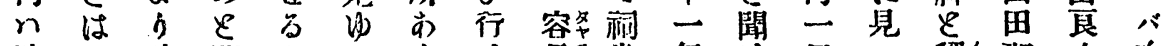

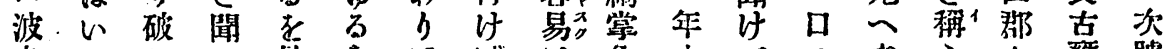

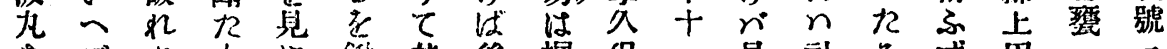
点

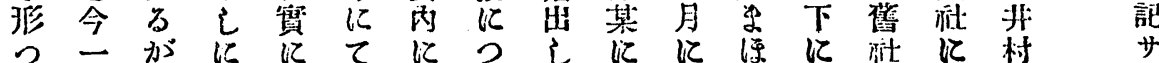

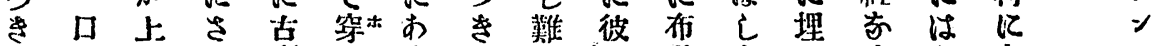

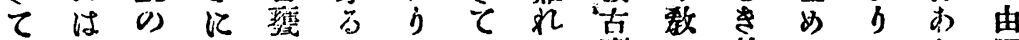

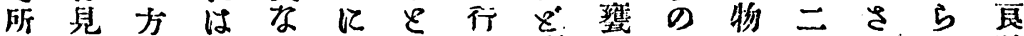
掯乞 $n$ 非

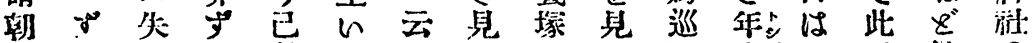

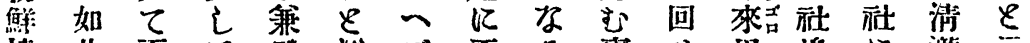

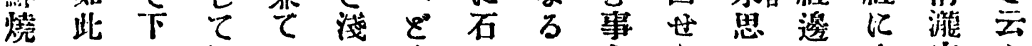

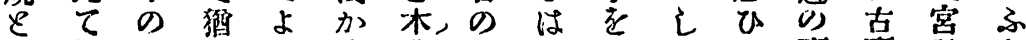
心例

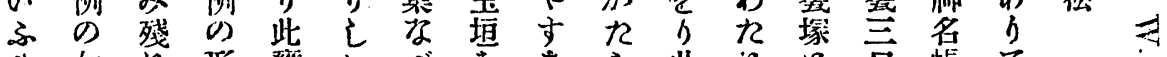

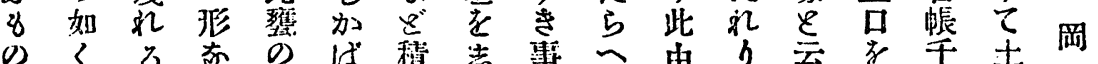

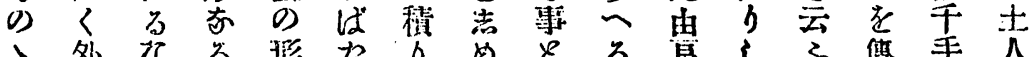

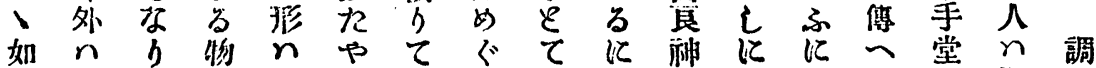

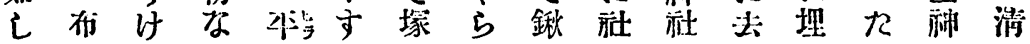

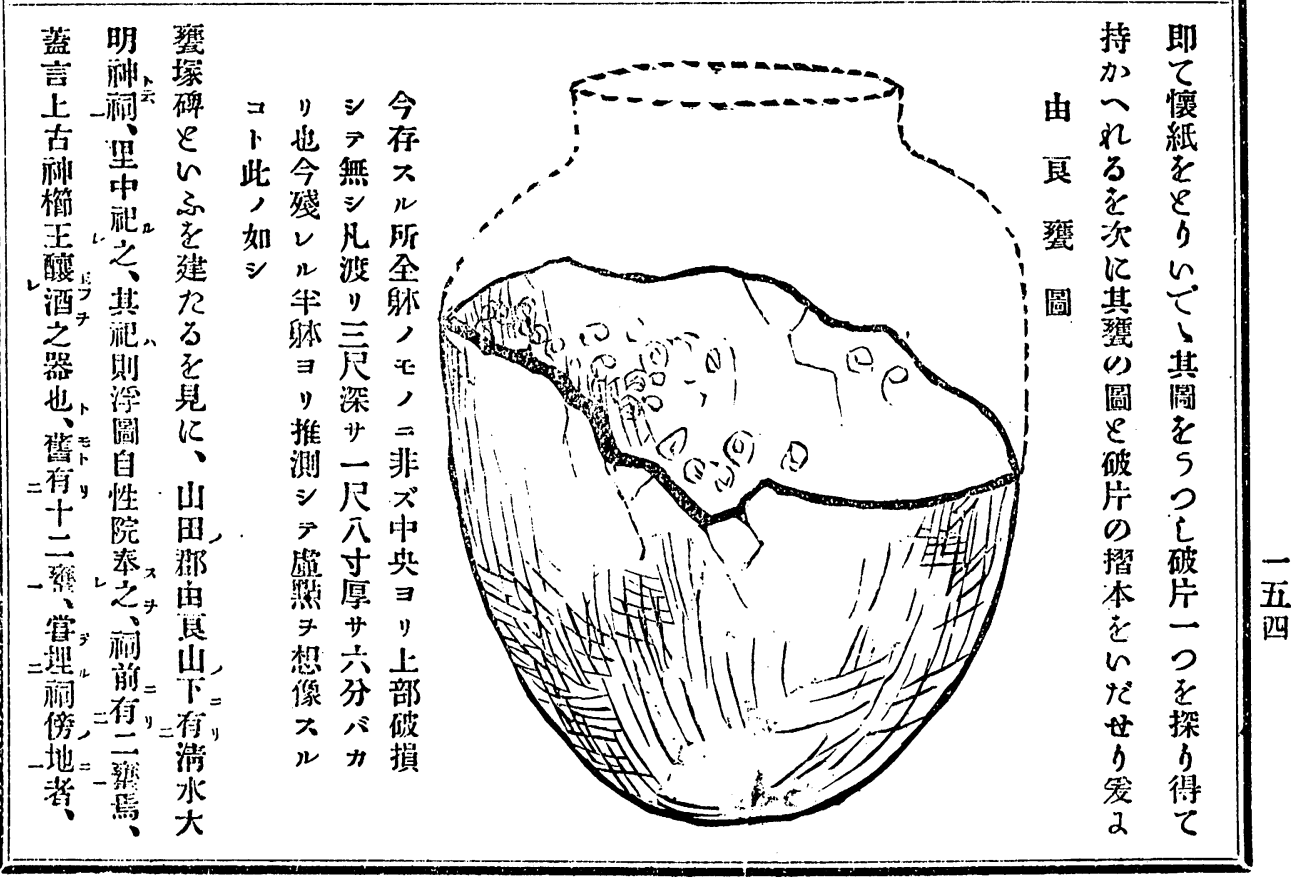

